\title{
Sleep medicine: a report from the recent ERS School Course
}

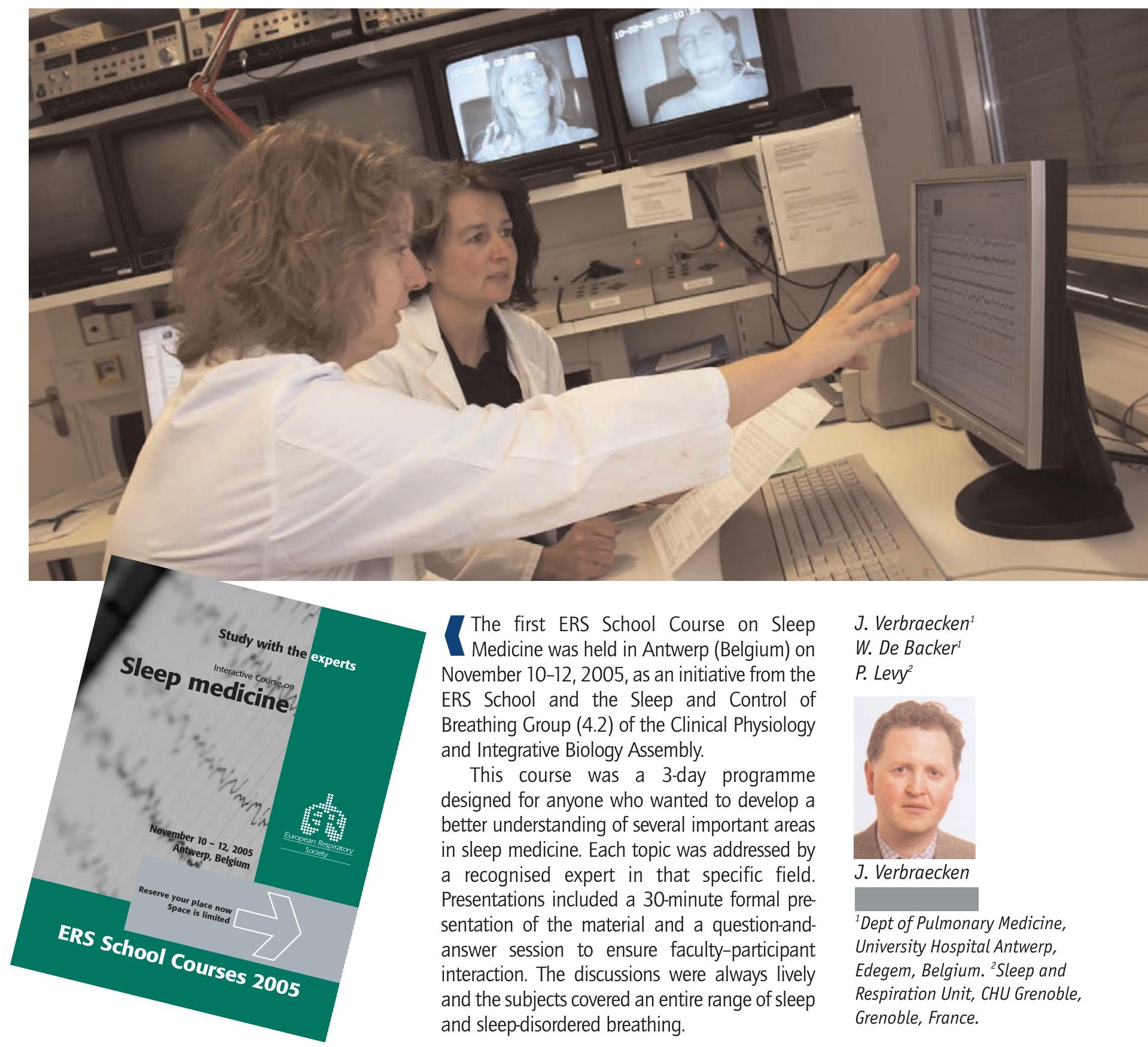




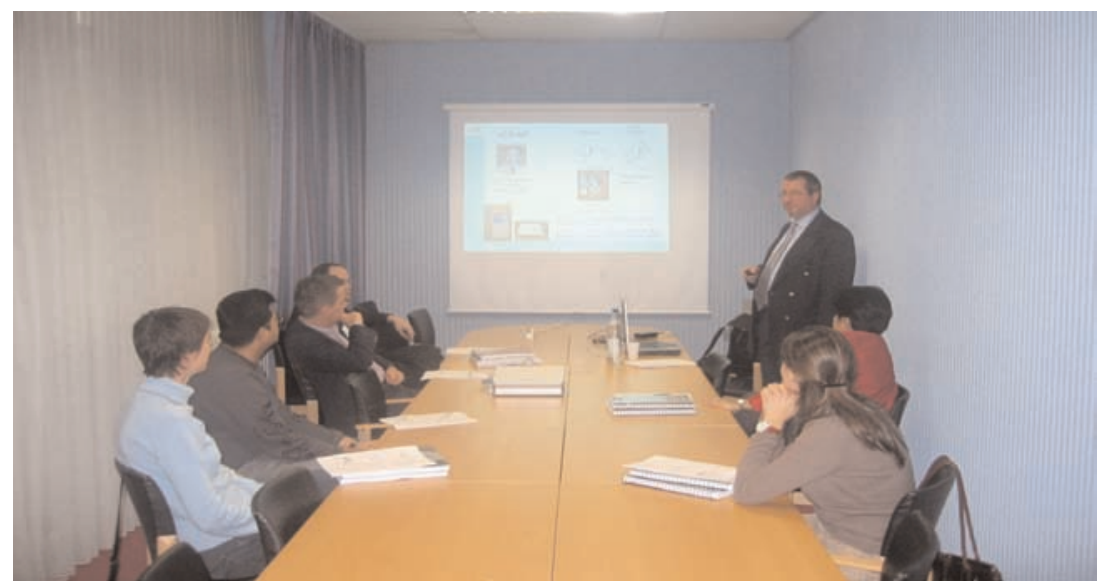

Workshop being held during the sleep course.
An attractive feature of this School Course was the high proportion of workshops on practical issues (electrode placement, EEG scoring and examples, screening, CPAP machines and masks, auto-CPAP and case studies), as well as the ready availability of the Faculty (Elke De Valck, Ellie Oostveen, Jose Montserrat, Daniel Rodenstein, Jean-Louis Pepin, Dirk Pevernagie, An Boudewyns, Olivier Vanderveken, Evert Hamans, Justin Pepperell, Veronique Viot-Blanc, Kristine Desager, Ilse De Volder, Bertine Buyse, Luc Melis, Patsie Wollaert, Marc Willemen, Johan Verbraecken, Wilfried De Backer and Patrick Levy).
A total of 74 attendees from 19 countries participated in the course, which resulted in a mix of academics and sleep medicine practitioners (62 from Europe and 12 from beyond Europe, from countries such as Saudi Arabia, Israel, Philippines, South Korea and South Africa).

The course evaluations indicated that this first ERS School Course on Sleep Medicine was very well received. Participants rated both the course as a whole and the various individual presentations as very good to excellent. All speakers were very impressed by the enthusiasm of the audience and their numerous questions. Overall, the course was a remarkable success, especially considering it was a firsttime effort. After the course, there was also a chance to enjoy the historical sightseeing in Antwerp.

As organisers, we would like to thank the faculty, who gave generously of their time and effort in presenting state-of-the-art material. The course could not have run without the hard work of the ERS Staff and Emlyn Stolting (ACS Projects, Amsterdam) who ensured that everything ran smoothly before and during the course. We would also like to thank the course participants who brought their interest and scientific curiosity to the course.

The presentations given at each session are available on the ERS website, at www.ersnet.org/elearning 